\title{
Supplements for Manuscript:
}

The MOSAiC Drift: Ice conditions from space and comparison with previous years

Lead authors: Thomas Krumpen ${ }^{1}$, Luisa von Albedyll ${ }^{1}$, Helge F. Goessling ${ }^{1}$, Stefan Hendricks ${ }^{1}$, Bennet 5 Juhls $^{1}$, Gunnar Spreen ${ }^{2}$, Sascha Willmes ${ }^{3}$

Co-authors: H. Jakob Belter ${ }^{1}$, Klaus Dethloff ${ }^{1}$, Christian Haas $^{1}$, Lars Kaleschke ${ }^{1}$, Christian Katlein ${ }^{1}$, Xiangshan Tian Kunze ${ }^{1}$, Robert Ricker ${ }^{1}$, Philip Rostosky ${ }^{2}$, Janna Rückert ${ }^{2}$, Suman Singha ${ }^{4}$, Julia Sokolova ${ }^{5}$

10

${ }^{1}$ Alfred Wegener Institute, Helmholtz Centre for Polar and Marine Research, Am Handelshafen 12, 27570 Bremerhaven, Germany

${ }^{2}$ University of Bremen, Institute of Environmental Physics, Otto-Hahn Allee 1, 28359 Bremen, Germany

${ }^{3}$ University of Trier, Environmental Meteorology, Universitätsring 15, 54296 Trier, Germany

$15{ }^{4}$ German Aerospace Center, Remote Sensing Technology Institute, SAR Signal Processing, Am Fallturm 9, 28359 Bremen, Germany

${ }^{5}$ Arctic and Antarctic Research Institute, Ulitsa Beringa, 38, Saint Petersburg, 199397, Russia 
a)
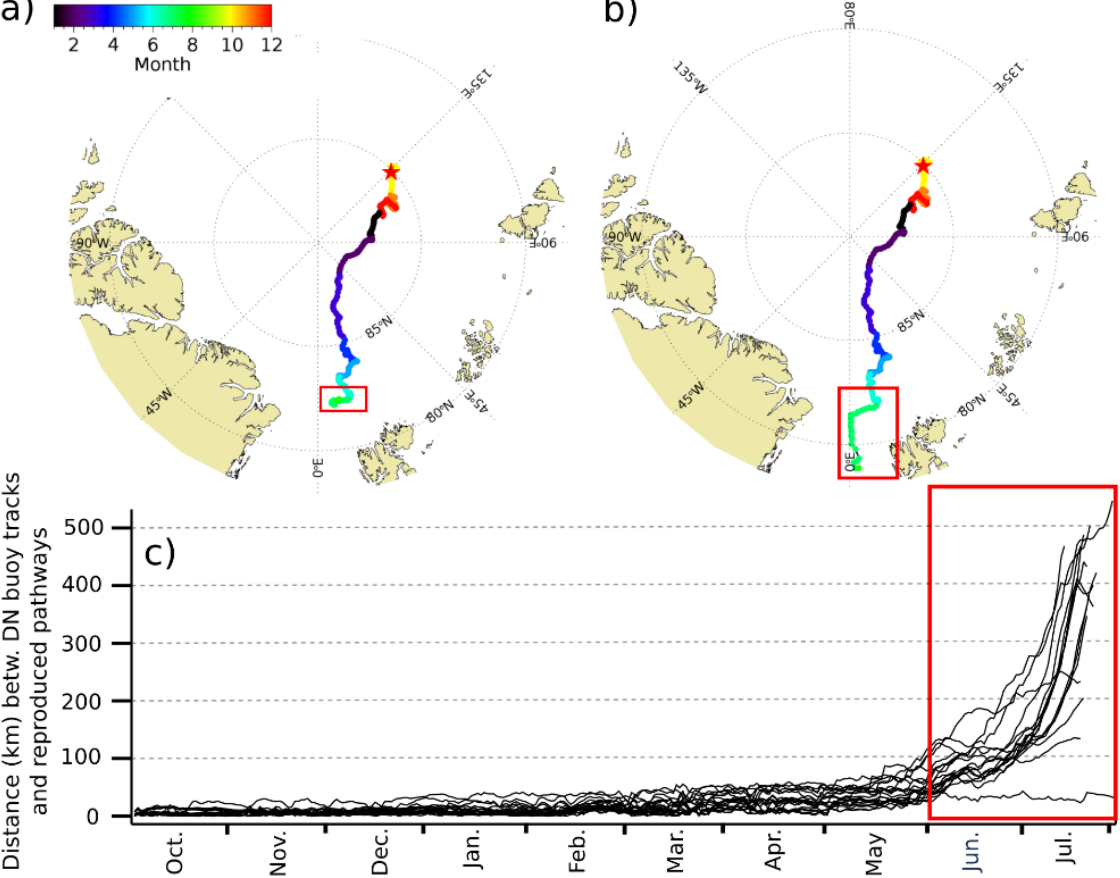

Figure S.1: Comparison of MOSAiC CO and DN buoy tracks with IceTrack results: a) Reproduced pathway of the CO with 25 IceTrack, b) Real (GPS-based) track of the CO, c) Distance between 23 DN buoys (source: seaiceportal.de) deployed on sea ice in the vicinity of the $\mathrm{CO}$ at the beginning of October 2019 and their reconstructed trajectories. Deviation between real and virtual tracks is small. Only once buoys enter Fram Strait (beginning of June $\left(240 \mathrm{~d}\right.$ ) at $\left.82.5^{\circ} \mathrm{N}\right)$, the displacement is gradually increasing. 

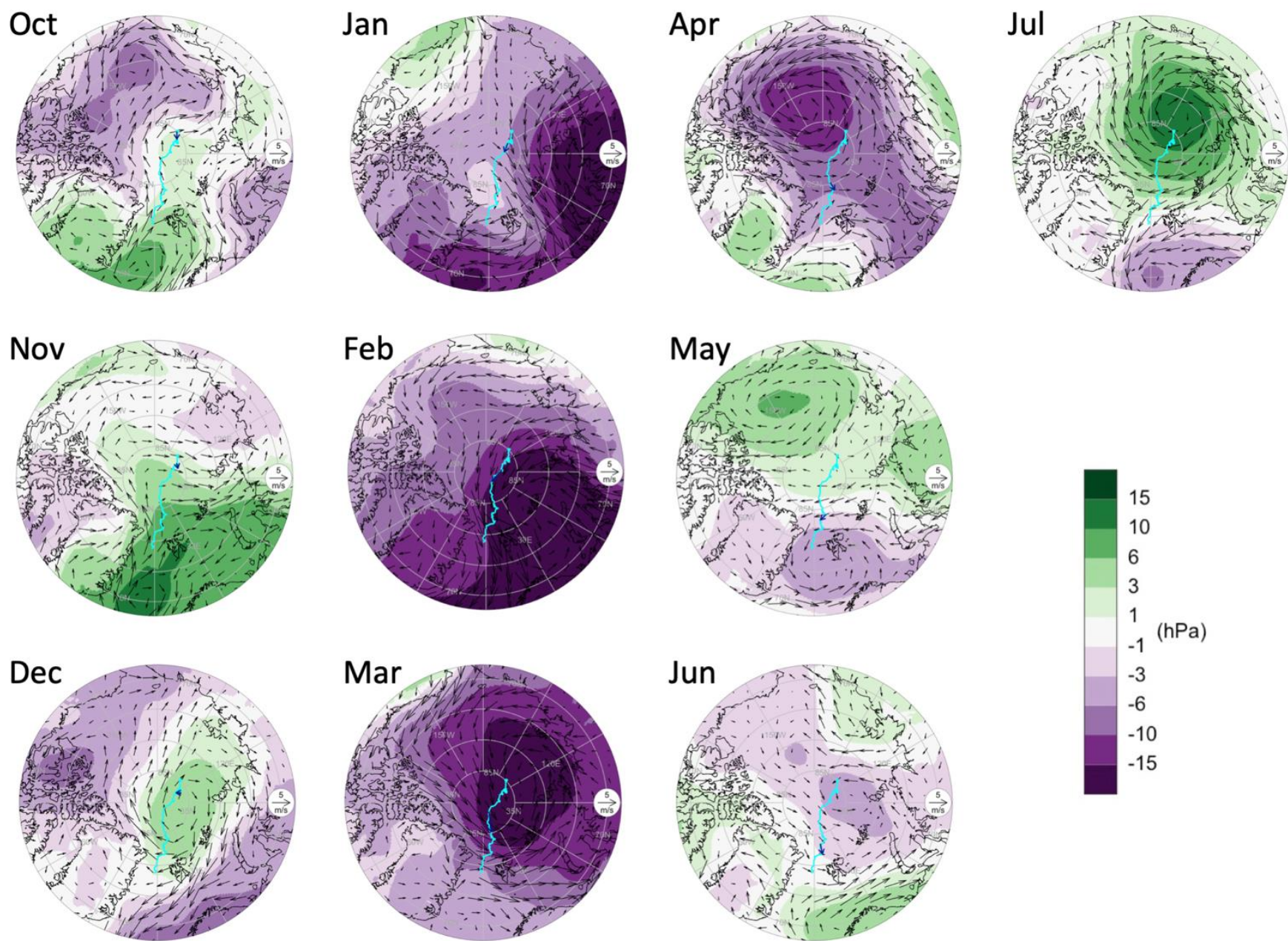

Figure S.2: Monthly-mean sea-level pressure (shading) and 10m wind (arrows) anomalies with respect to the reference period 2005-2019 for each month of the MOSAiC drift from October 2019 to July 2020. The complete drift path is denoted by cyan lines; the drift during the respective month is denoted by blue arrows. 

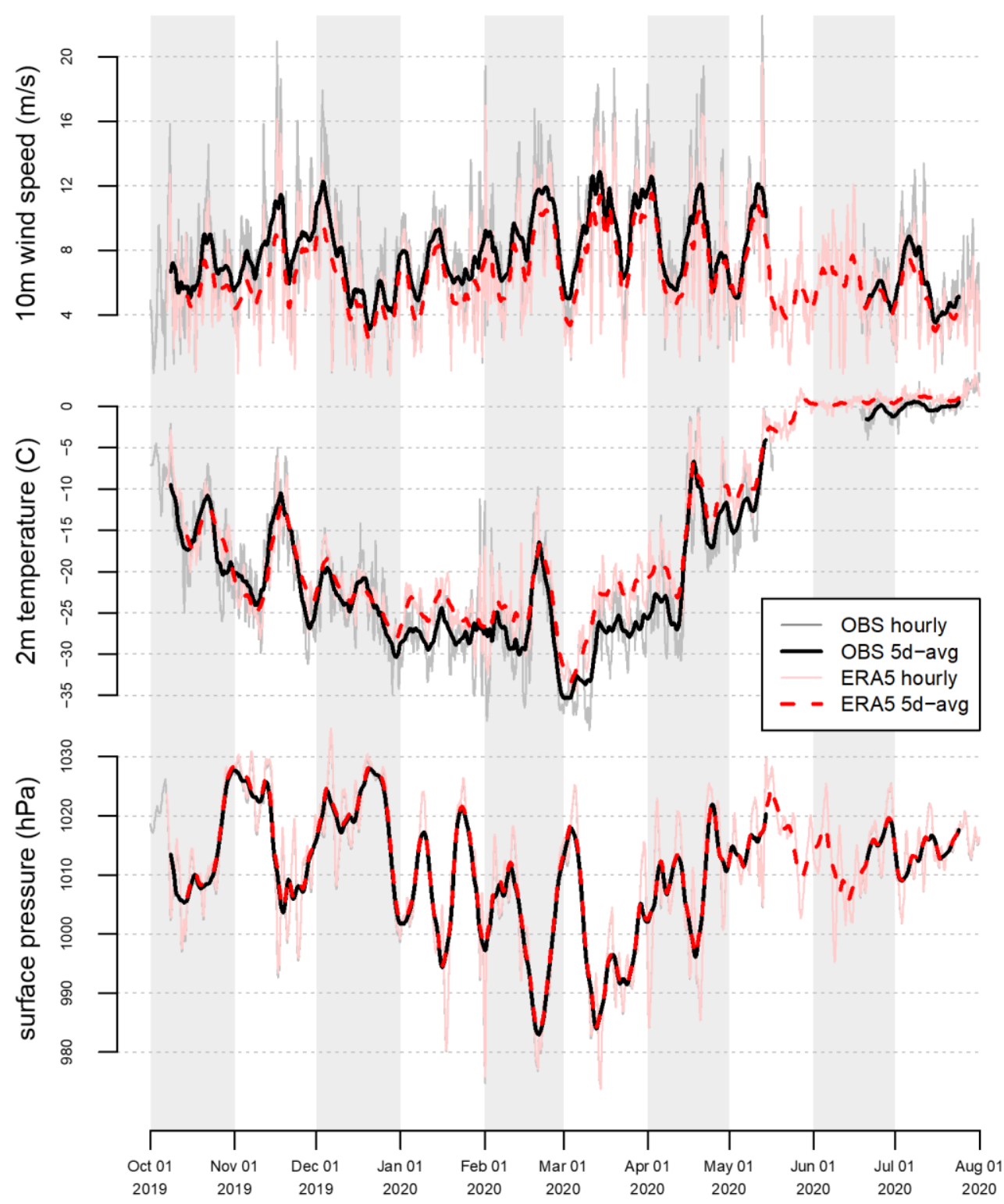

Figure S.3: Atmospheric conditions along the MOSAiC drift trajectory in 2019/20 according to ERA5 (red and light red) and according to ship measurements (black and grey). Hourly data are depicted in light red and grey; 5-days-averages are depicted in red (dashed) and black. Top: $10 \mathrm{~m}$ wind speed; Middle: $2 \mathrm{~m}$ temperature; Bottom: surface pressure. 
Sea Ice Concentration

40

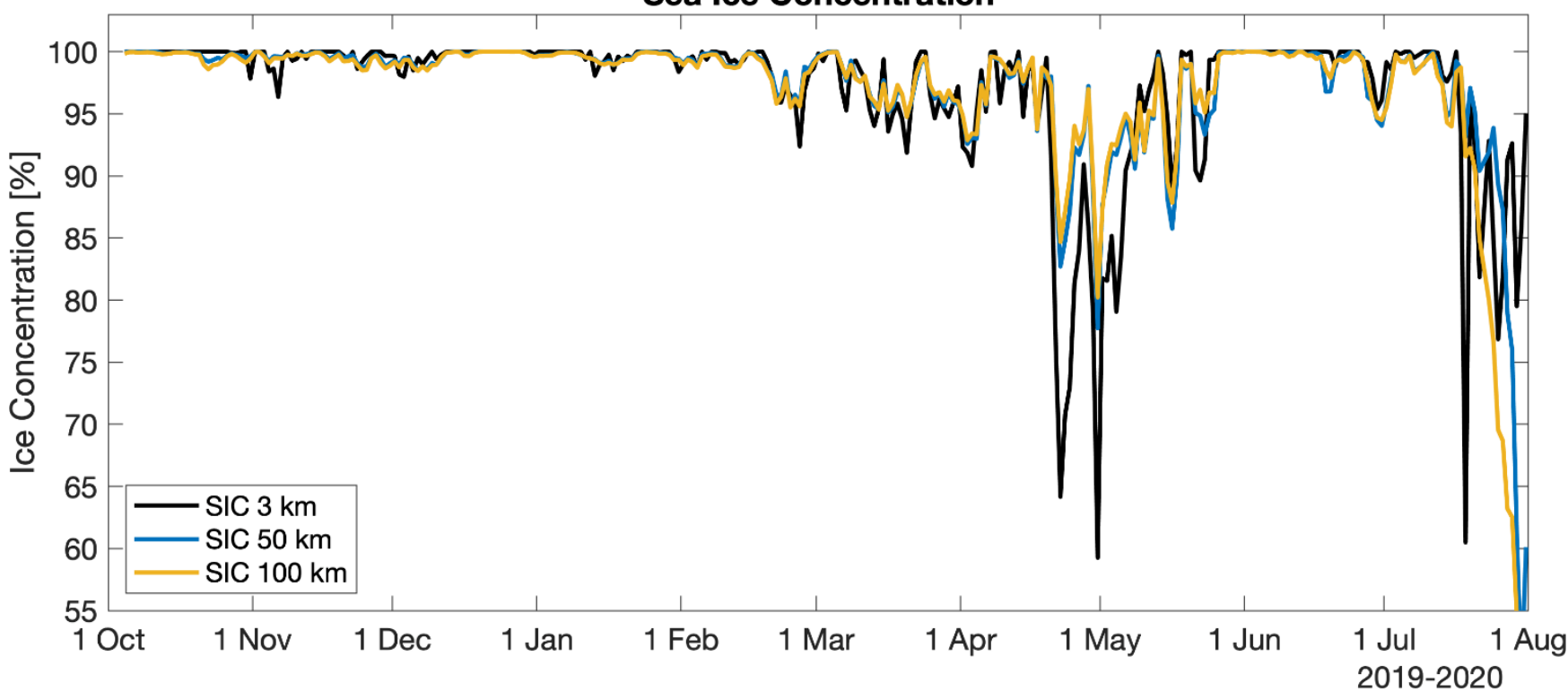

Figure S.4: Sea-ice concentration (SIC) along the MOSAiC drift trajectory from the start of the drift on $4^{\text {th }}$ October 2019 until the end of the first floe on July 31 2020. Daily (no smoothing) sea-ice concentrations are shown at 3.125 (black), 50 (blue), and $100 \mathrm{~km}$ (yellow) radius. Please mind the significantly underestimated concentrations between mid-April to May and associated discussion in the main text and Figure 5. 


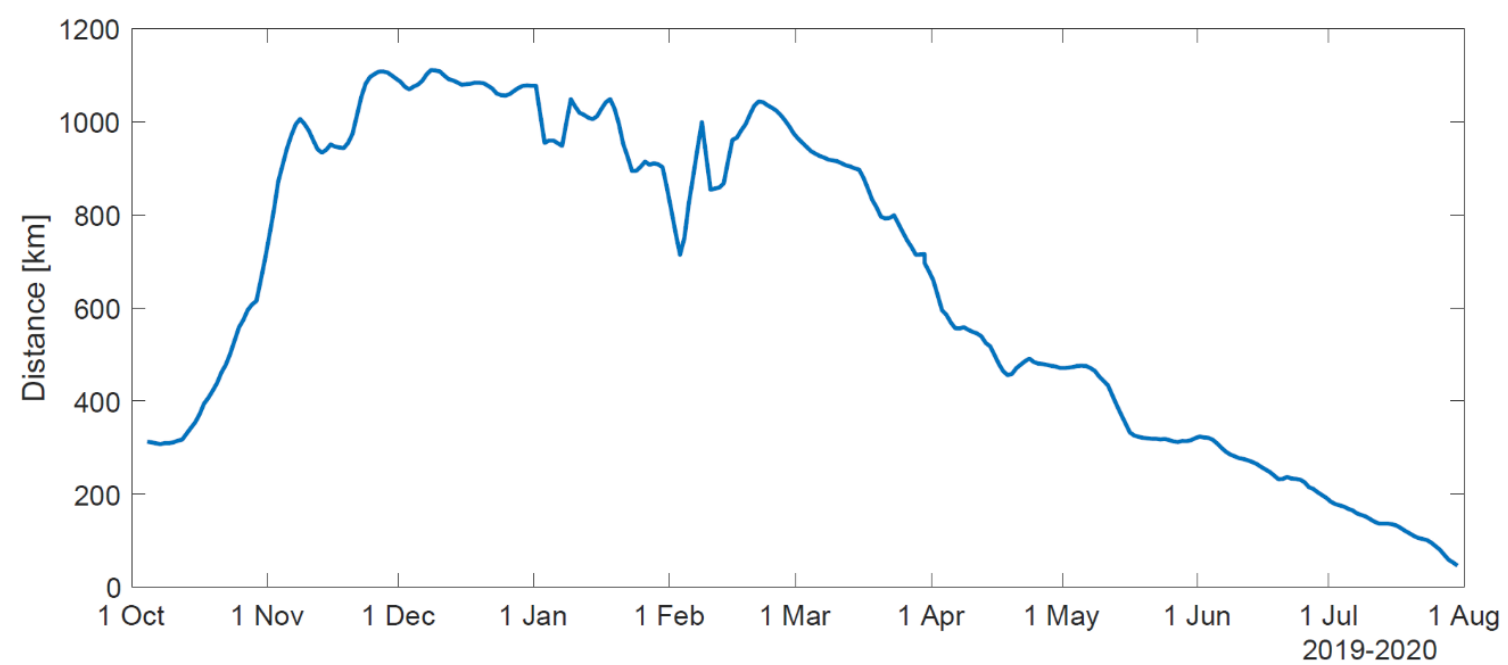

Figure S.5: Distance of the MOSAiC CO to the ice edge obtained from the sea-ice concentration data set. 


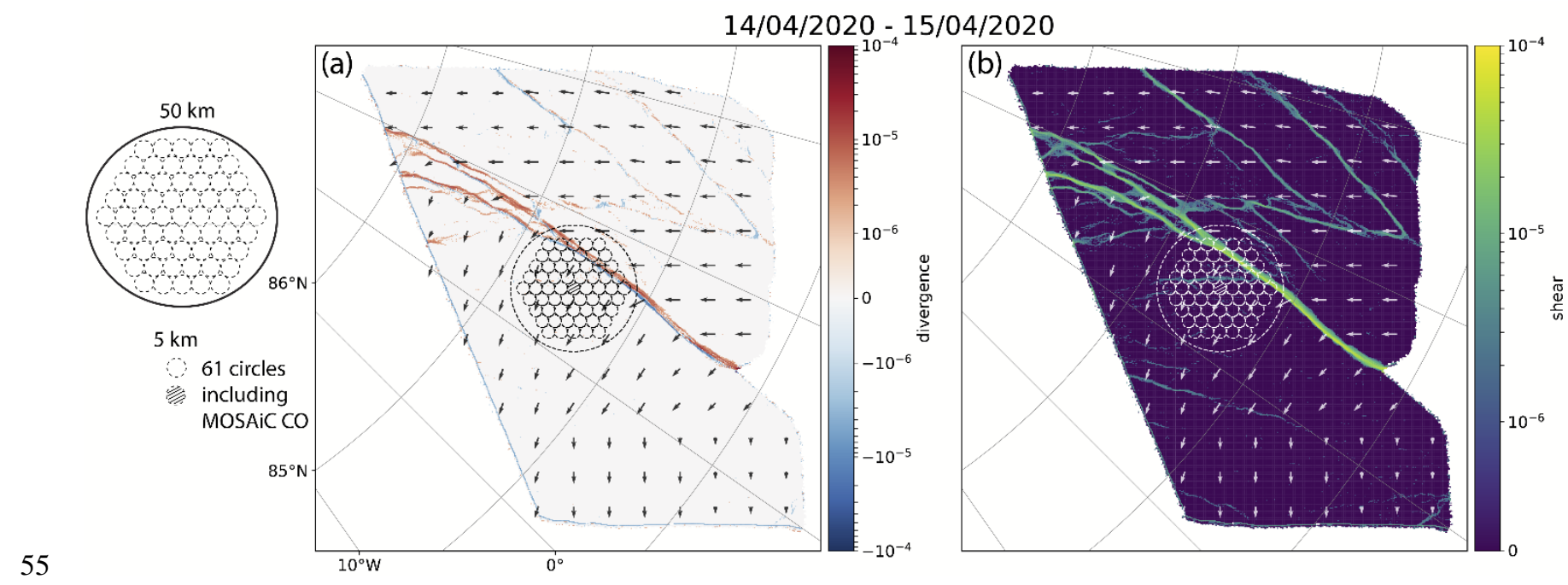

Figure S.6: Left: To compare deformation in the vicinity of the ship $(5 \mathrm{~km})$ with deformation at larger distances $(50 \mathrm{~km})$, averages were computed for $61 \times 5 \mathrm{~km}$ circles arranged within a radius of $50 \mathrm{~km}$ around the ship. Centre/right: Example of divergence (middle) and shear (right) derived from two consecutive Sentinel-1 SAR images acquired on April 14 (07:26:14) and 15 (08:07:03) 2020. Sea ice motion is displayed as black arrows. The image pair shows the strongest deformation event observed: Within 24 hours, a $2.5 \mathrm{~km}$ wide north-south oriented lead opened up $\sim 25 \mathrm{~km}$ away from the CO. 